\title{
The Role of Noninvasive Neuromodulation in Migraine Management
}

\author{
Francesca Puledda ${ }^{1,2}$ and Peter J Goadsby ${ }^{1}$ \\ 1. National Institute for Health Research/Wellcome Trust King's Clinical Research Facility, King's College London, UK; 2. Department of \\ Neurology and Psychiatry, Sapienza University of Rome, Italy
} migraine, providing a valid alternative option for patients for whom traditional drugs have failed, or for those who do not tolerate their side effects. This brief review aims at describing noninvasive neuromodulation techniques, which are currently the most used in clinical practice, specifically focusing on transcranial magnetic stimulation, vagus nerve stimulation and supraorbital nerve stimulation.

\section{Keywords}

Migraine, neuromodulation, transcranial magnetic stimulation (TMS), transcutaneous vagus nerve stimulation (nVNS), transcutaneous supraorbital nerve Stimulation

Disclosure: Peter J Goadsby reports personal fees from Ajinomoto Pharmaceuticals Co, Akita Biomedical, Alder Biopharmaceuticals, Avanir Pharma, Cipla Ltd, Colucid Pharmaceuticals, Ltd, Dr Reddy's Laboratories, Electrocore LLC, Ethicon, US, WL Gore \& Associates, Heptares Therapeutics, Nupathe Inc, Pfizer Inc, Promius Pharma, Scion, Teva Pharmaceuticals, MedicoLegal work, Journal Watch, Up-toDate, Oxford University Press, Autonomic Technologies Inc. and Novartis. Grants and personal fees from Allergan, Amgen, Eli-Lilly and Company, eNeura Inc, Trigemina Inc., outside the submitted work. In addition, Peter J Goadsby has a patent Magnetic stimulation for headache pending to eNeura. Francesca Puledda has nothing to declare in relation to this article. No funding was received for the publication of this article.

Authorship: All named authors meet the International Committee of Medical Journal Editors (ICMJE) criteria for authorship of this manuscript, take responsibility for the integrity of the work as a whole, and have given final approval to the version to be published.

Compliance with Ethics: The analysis in this article is based on previously conducted studies, and does not involve any new studies of human or animal subjects performed by any of the authors.

Open Access: This article is published under the Creative Commons Attribution Noncommercial License, which permits any non-commercial use, distribution, adaptation and reproduction provided the original author(s) and source are given appropriate credit.

Received: 14 April 2016

Accepted: 10 September 2016

Citation: European Neurological Review, 2016;11(2):106-8

Corresponding Author: Peter J Goadsby, Wellcome Foundation Building King's College Hospital, London, SE5 9PJ, UK. E: peter.goadsby@kcl.ac.uk
Migraine is the sixth most common form of disability globally that affects young, otherwise healthy subjects at the peak of their productive years. ${ }^{1}$ The management of chronic or refractory migraine with traditional pharmacological approaches can often prove challenging and unsatisfactory. In recent years, migraine therapy has witnessed rapid advance of techniques that offer a valid alternative to the common preventive treatments, with generally limited and tolerable side effects.

Noninvasive neuromodulation approaches act through the transcutaneous stimulation of either cortical areas or peripheral nerves that are involved in pain. They allow to extend a treatment previously reserved to a select subgroup of patients also to sufferers experiencing less severe forms of migraine, who nonetheless desire avoiding the common side effects caused by medication.

\section{Transcranial magnetic stimulation}

Transcranial magnetic stimulation (TMS) is a noninvasive technique that was first discovered in $1985 .{ }^{2}$ It is applied externally to the scalp and creates a fluctuating magnetic field capable of inducing an electrical current to the underlying cerebral cortex, which in turn has the effect of changing the firing pattern of neurons. TMS has been shown to disrupt the wave of cortical spreading depression (CSD), which is thought to be the experimental correlate of migraine aura. ${ }^{3.4} \mathrm{CSD}$ may indeed induce head pain via cortico-thalamic circuits. ${ }^{.}$TMS has been used in a variety of research and clinical settings, including headache, mainly because of its safety and non-invasiveness. ${ }^{6,7}$ It can be delivered as one pulse or as trains of repeated stimulations; single-pulse TMS (STMS) has been studied as a treatment for acute and prophylactic therapy in migraine, while fewer studies have evaluated the effect of repetitive TMS (rTMS).

A preliminary study using table-top STMS device had shown good tolerability and efficacy in treating acute attacks in 42 migraine patients. ${ }^{8}$ A more feasible, hand-held STMS device was tested in a randomised controlled trial (RCT) involving 164 migraine with aura patients.? In this study, two TMS pulses separated by a 30-second interval were administered over the occipital cortex to treat a migraine with aura attack within one hour of symptom onset. TMS showed a 17\% gain in pain-free rates at two hours with respect to the sham stimulation (39 vs. $22 \%)$. The effect was sustained at 24 and 48 hours. Given these positive results, a portable sTMS device has been approved by the Food and Drug Administration in the USA and Conformité Européen (CE) marked in Europe for the acute treatment of migraine with aura. A post-market pilot programme was performed in the UK to assess the impact of a 
Table 1: Summary of reviewed studies for noninvasive neuromodulation in migraine

\begin{tabular}{|c|c|c|c|c|c|}
\hline Device & Treatment & Author, year & Patients & Migraine diagnosis & Clinical study \\
\hline TMS (Cerena STMS ${ }^{\circledR}$ ) & Acute & Lipton et al. $2010^{9}$ & $n=164$ & Episodic with aura & RCT \\
\hline TMS (SpringTMS ${ }^{\circledR}$ ) & Acute & Bhola et al. $2015^{10}$ & $n=190$ & Episodic/Chronic with/without aura & Post-market Pilot \\
\hline nVNS (GammaCore ${ }^{\circledR}$ ) & Acute & Goadsby et al. $2014^{19}$ & $n=27$ & Episodic with/without aura & Open-label single-arm \\
\hline nVNS (GammaCore ${ }^{\circledR}$ ) & Acute & Barbanti et al. $2015^{20}$ & $n=48$ & HF Episodic/Chronic with/without aura & Open-label single-arm \\
\hline nVNS (GammaCore ${ }^{\circledR}$ ) & Preventative & Silberstein et al. $2014^{21}$ & $n=59$ & Chronic with/without aura & $\mathrm{RCT}$ \\
\hline SNS (Cefaly $\left.{ }^{\circledR}\right)$ & Preventative/acute & Schoenen et al. $2013^{24}$ & $n=67$ & Chronic with/without aura & RCT \\
\hline
\end{tabular}

nVNS = transcutaneous vagus nerve stimulation; RCT = randomised controlled trial; SNS = supraorbital neurostimulation; TMS = transcranial magnetic stimulation

three-month treatment with SpringTMS ${ }^{\circledR}$ (eNeura, Baltimore, US) on migraine patients with and without aura, both episodic and chronic. ${ }^{10}$ A total of 190 patients were involved, and the overall effect of STMS was positive: there was a significant reduction of migraine days and attack duration, as well as a decrease in disability scores. No serious adverse events were reported. Furthermore, the study showed that the positive effect of TMS develops more the longer the treatment continues. A similar observational study is currently ongoing in the US and is aimed at evaluating the efficacy of STMS in migraine with or without aura (NCT02357381). An RCT testing the use of rTMS over the visual cortex in preventing chronic migraine is also ongoing (NCT02122744). Limitations to the use of STMS come from the observation that the main study exploring its efficacy was exclusively directed to aura patients; as in all device trials, it is also difficult to exclude a certain degree of unblinding although this was very well balanced in this study. The second study, although directed to a broader population of migraine patients, was not a RCT.

\section{Transcutaneous vagus nerve stimulation}

Invasive vagus nerve stimulation (VNS) was initially used as a treatment for epilepsy ${ }^{11}$ and depression; ${ }^{12}$ interestingly, its effect on headache was first suggested by observing a reduction in the frequency of migraine attacks - and not seizures - in a patient who was implanted with a VNS device for epilepsy; ${ }^{13}$ other preliminary reports further confirmed this result. ${ }^{14-16}$ The positive outcome of VNS on headache led to the development of a portable transcutaneous non-invasive device (GammaCore ${ }^{\circledR}$; electroCore, New Jersey, US), which when administered on the neck stimulates the cervical portion of the vagus nerve by producing a mild electrical current then transmitted through the skin. The effect of transcutaneous vagus nerve stimulation (nVNS) has been studied in both the acute and preventive treatment of migraine, with generally mild and well-tolerated side effects such as skin redness, raspy voice and neck twitching.

The wide anatomical and physiological connections of the vagus nerve to major pain centres of the brain - with its afferents terminating in the trigeminal nucleus caudalis and dural nociceptive fibres being received by the nucleus tractus solitarius - may explain the effect of nVNS on headache, ultimately through a reduction of glutamate levels and neuronal firing in the spinal trigeminal nucleus ${ }^{17,18}$ and therefore by an ascending antinociceptive effect on the trigeminal nuclear complex.

An initial open-label single-arm pilot study investigated the use of nVNS in acute migraine attacks ${ }^{19}$ in 27 patients with episodic migraine. A total of 80 attacks were treated with two unilateral 90-second doses, separated by 15 -minute intervals. Of the 54 moderate or severe attacks, $22 \%$ were completely aborted at two hours, while $43 \%$ had a significant reduction in pain scores. A further study gave similar results in 48 patients with high-frequency episodic and chronic migraine, confirming the positive effect of nVNS as an acute treatment..$^{20}$ The use of nVNS in prevention of migraine has also shown promising results. The recent report from the EVENT study, a double-blind, sham-controlled pilot study in chronic migraine, showed that treatment with two 90-second doses administered three times a day caused a reduction of approximately two headache days per month in the treatment group, compared to no change in the sham group. This reduction reached almost nine days after the six-month open-label phase, compared to 5.5 in those initially assigned to sham, suggesting that long-term prophylaxis might be needed. ${ }^{21}$ Another open-label report on patients with episodic and chronic migraine showed an overall reduction of almost six headache days per month after a three-month nVNS preventive treatment. ${ }^{22}$ A randomised sham-controlled study for episodic migraine prevention is currently ongoing (NCT02378844). Future trials to confirm these results are warranted, given that the studies treated relatively small numbers of patients and that the double-blind phase for the only available RCT showed a somewhat modest reduction in headache days.

\section{Transcutaneous supraorbital nerve stimulation}

The use of transcutaneous electrical current administered to cutaneous sensory or cranial nerves for the treatment of headache has been applied for many years, and reappeared in the modern literature as long as 30 years $\mathrm{ago}^{23}$ although its use has been limited because of conflicting results.

A novel technique based on the application of electrical current to the supraorbital nerve has recently been studied for migraine prevention in a randomised controlled trial. ${ }^{24}$ This RCT tested the use of a supraorbital transcutaneous stimulator called the Cefaly ${ }^{\circledR}$ device (Cefaly Technology, Nuneaton, UK), applied bilaterally for 20 minutes daily for three months to the supraorbital and supratrochlear nerves, in 67 migraine patients. The treatment group showed a significant reduction in headache days, migraine attacks and use of abortive medications in respect to the sham group. Subsequently, a large survey was performed on 2,313 patients using the device, showing only minor adverse events and an overall high safety and satisfaction with treatment. ${ }^{25}$ Pitfalls in the study include unblinding caused by paresthesias induced by the device, which are quite noticeable and uncomfortable, as well as a relatively small improvement measured in terms of number of headache days. In 2014, the FDA gave nonetheless approval for the use of Cefaly device in the prevention of migraine, and the device is also CE-marked in Europe.

\section{Conclusions}

Noninvasive neuromodulation is an exciting and useful method that is being increasingly recognised as a valid strategy for migraine management. It not only offers a safe and effective alternative to pharmacological treatments, but also provides interesting insights into the biology of migraine itself. Further RCTs need to be undertaken in the future, however, to confirm these promising results. $\square$ 
1. Global Burden of Disease Study 2013 Collaborators, Global, regional, and national incidence, prevalence, and years lived with disability for 301 acute and chronic diseases and injuries with disability for 301 acute and chronic diseases and injuries
in 188 countries, 1990-2013: a systematic analysis for the in 188 countries, 1990-2013: a systematic analysis for the
Global Burden of Disease Study 2013, Lancet, 2015;386:743Global

2. Barker $A T$, Jalinous R, Freeston IL, Non-invasive magnetic stimulation of human motor cortex, Lancet, 1985; 1(8437):1106-7.

3. Leão AAP, Spreading depression of activity in the cerebral cortex, J Neurophysiol, 1944;7:359-90.

4. Lauritzen M, La Dreier JP, Fabricius M, et al., Clinical relevance of cortical spreading depression in neurological disorders: migraine, malignant stroke, subarachnoid and intracranial hemorrhage, and traumatic brain injury, J Cereb Blood Flow Metab, 2011;31:17-35.

5. Andreou AP, Holland PR, Akerman S, et al., Transcranial Magnetic Stimulation and Potential Cortical and Trigeminothalamic

6. Dodick DW, Schembri CT, Helmuth M, Aurora SK, Transcranial magnetic stimulation for migraine: a safety review, Headache, 2010:50:1153-63

7. Wassermann $\mathrm{EM}$, Risk and safety of repetitive transcranial magnetic stimulation: report and suggested guidelines from the International Workshop on the Safety of Repetitive Transcrania Magnetic Stimulation, June 5-7, 1996, Electroencephalogr Clin Neurophysiol, 1998;108:1-16

8. Clarke BM, Upton AR, Kamath MV, et al., Transcranial magnetic stimulation for migraine: clinical effects, J Headache Pain,
2006;7:341-6.

9. Lipton RB, Dodick DW, Silberstein SD, et al. Single-pulse transcranial magnetic stimulation for acute treatment of migraine with aura: a randomised, double-blind, parallel-group rollod rial, Lancet Neurol, 2010:9.373-80.

10. Bhola R, Kinsella E, Giffin N, et al., Single-pulse transcranial magnetic stimulation (STMS) for the acute treatment of migraine: evaluation of outcome data for the UK post market pilot program, J Headache Pain, 2015;16:535.

11. Kirchner A, Birklein F, Stefan $\mathrm{H}$, Handwerker HO, Left vagus nerve stimulation suppresses experimentally induced pain, Neurology, 2000;55:1167-71.

12. Yuan TF, Li A, Sun $\mathrm{X}$, et al., Vagus nerve stimulation in treating depression: A tale of two stories, Curr Mol Med, 2016:16(1):33-9.

13. Sadler RM, Purdy RA, Rahey S, Vagal nerve stimulation aborts migraine in patient with intractable epilepsy, Cephalalgia, 2002;22:482-4.

14. Mauskop A, Vagus nerve stimulation relieves chronic refractory migraine and cluster headaches, Cephalalgia, 2005;25(2):82-6.

15. Lenaerts ME, Oommen KJ, Couch JR, Skaggs V, Can vagus nerve stimulation help migraine?, Cephalalgia, 2008;28(4):392-5.

16. Cecchini AP, Mea E, Tullo V, et al., Vagus nerve stimulation in drug-resistant daily chronic migraine with depression: preliminary data, Neurol Sci, 2009;30 (Suppl 1):S101-4.

17. Oshinsky ML, Murphy AL, Hekierski H, Jr., et al., Noninvasive vagus nerve stimulation as treatment for trigeminal allodynia, Pain, 2014;155:1037-42.

18. Lyubashina OA, Sokolov AY, Panteleev SS, Vagal afferent modulation of spinal trigeminal neuronal responses to dural electrical stimulation in rats, Neuroscience, 2012;222:29-37.

19. Goadsby PJ Grosberg BM, Mauskop A et al. Effect of noninvasive vagus nerve stimulation on acute migraine: an open-label pilot study, Cephalalgia, 2014;34:986-93,

20. Barbanti P, Grazzi L, Egeo G, et al., Non-invasive vagus nerve stimulation for acute treatment of high-frequency and chron migraine: an open-label study, J Headache Pain, 2015;16:61.

21. Silberstein SD, Da Silva AN, Calhoun $A H$, et al., Non-invasive vagus Nerve Stimulation for Chronic Migraine Prevention in a Prospective, Randomized, Sham-Controlled Pilot Study (the EVENT Study): Report from the Open-label Phase, Headache 2014;54(Suppl S1).

22. Kinfe TM, Pintea B, Muhammad S, et al., Cervical non-invasive vagus nerve stimulation (nVNS) for preventive and acute treatment of episodic and chronic migraine and migraineassociated sleep disturbance: a prospective observationa cohort study, J Headache Pain, 2015;16:101.

23. Koehler PJ, Boes CJ, A history of non-drug treatment in hoehler PJ, Boes CJ, A history of non-drug treatment in
headache, particularly migraine, Brain, 2010;133(Pt 8):2489-500

24. Schoenen J, Vandersmissen B, Jeangette S, et al., Migraine prevention with a supraorbital transcutaneous stimulator: a randomized controlled trial, Neurology, 2013;80(8):697-704.

25. Magis D, Sava S, d'Elia TS, et al., Safety and patients' satisfaction of transcutaneous supraorbital neurostimulation (tSNS) with the Cefaly $(R)$ device in headache treatment: a survey of 2,313 headache sufferers in the general population, J Headache Pain 2013;14:95 